\title{
Exploitation of the Coil-Globule Plasmid DNA Transition Induced by Small Changes in Temperature, pH Salt, and Poly(ethylene glycol) Compositions for Directed Partitioning in Aqueous Two-Phase Systems
}

\author{
Andreas Frerix, ${ }^{\dagger}$ Michael Schönewald,${ }^{\dagger}$ Petra Geilenkirchen, ${ }^{\dagger}$ Markus Müller,${ }^{\S}$ \\ Maria-Regina Kula, ${ }^{\ddagger}$ and Jürgen Hubbuch*,† \\ Institut für Biotechnologie 2, Forschungszentrum Jülich, 52426 Jülich, Germany, Institut für \\ Enzymtechnologie, Heinrich-Heine Universität Düsseldorf, 52426 Jülich, Germany, and Qiagen GmbH, \\ Max-Volmer-Strasse 4, 40724 Hilden, Germany
}

Received October 11, 2005. In Final Form: February 9, 2006

\begin{abstract}
In this study, the interplay of two linked equilibria is examined, one concerning an aqueous two-phase system (ATPS) composed of poly(ethylene glycol) (PEG) and salt employed to partition plasmid DNA (pDNA), and the other a potential structural transition of pDNA depending on PEG and salt concentration and other system parameters. The boundary conditions for pDNA partitioning are set by PEG and salt concentrations, PEG molecular weight, $\mathrm{pH}$, and temperature. While investigating these parameters, it was found that a small increase/decrease of the respective values led to a drastic and significant change in pDNA behavior. This behavior could be attributed to a coil-globule transition of the pDNA triggered by the respective phase conditions. The combination of this structural change, aggregation effects linked to the transition process, and the electrostatic potential difference found in PEG-salt systems thus offers a sensitive way to separate nucleic acid forms on the basis of their unique property to undergo coil-globule transitions under distinct system properties.
\end{abstract}

\section{Introduction}

Future developments in gene therapy may have the potential to challenge diseases that yet await treatment on a molecular basis. Using plasmid DNA (pDNA) as a vector for transferring prophylactic and/or therapeutic genes has become relevant since safety concerns with viral vectors attributed to immunological reactions were raised (see ref 1 ). The application of pDNA is, however, hampered by low efficiency during transfer and has only a short duration of expression. ${ }^{2}$ This increases the required amounts for a full treatment to several milligrams of DNA, and thus scalable purification processes are required for providing large amounts of pDNA of pharmaceutical-grade quality at moderate costs.

Any given purification process in the downstream processing of biological molecules uses differences (however small) in the specific surface properties or structural characteristics between the target molecule and the contaminants present. In this respect, separation of pDNA, genomic DNA (gDNA), and RNA represents an especially difficult task because of the chemical similarities of the components. All of them have in common that they can be characterized by high molecular weight, chainlike structure, and polyanionic charge and, thus, may be treated in a manner similar to that of negatively charged polymeric structures. pDNA itself shows different conformations such as open circular, multimeric, and supercoiled forms; the latter seems to be more effective for transferring genes and their expression. ${ }^{3}$

In downstream processing, polymer-salt or polymer-polymer mixtures are used because of their ability to form aqueous two-

\footnotetext{
* Corresponding author. E-mail: j.hubbuch@fz-juelich.de.

Forschungszentrum Jülich.

$\doteqdot$ Heinrich-Heine Universität Düsseldorf.

$\S$ Qiagen $\mathrm{GmbH}$.

(1) Fox, J. L. Gene therapy safety issues come to fore. Nat. Biotechnol. 1999, $12,1153$.

(2) Crystal, R. G. The gene as the drug. Nat. Med. 1995, 1, 15-17.

(3) Marquet, M.; Horn, N. C.; Meek, J. A. Characterization of plasmid DNA vectors for use in human gene therapy. BioPharm 1997, 10, 42-50.
}

phase systems (ATPSs), provided that the concentrations of the respective components lie above a critical value. The phase separation of polymer/polymer systems such as poly(ethylene glycol) (PEG)/dextran are based on the incompatibility of large hydrophilic polymers, while, for polymer-salt systems such as PEG/potassium phosphate phase separation, it is based on the salting-out effect of the respective salt for the polymer. The respective affinities for various components of either phase allow selective partitioning and thus purification of a given target from other components. It was previously shown that ATPSs are suitable for scalable and effective pDNA processing, ${ }^{4-6}$ being able to separate different nucleic acid forms, RNA from pDNA, or even distinguish between different pDNA forms. During earlier studies, it was already indicated that the partitioning behavior of pDNA might be closely related to a structural rearrangement related to fluid-phase conditions. ${ }^{4-7}$

A unique property of DNA structures is their ability to collapse into compact, orderly particles containing a single or a low number of molecules. The 4.2 million base pairs of the E. coli chromosome, for example, extend to $1.4 \mathrm{~mm}$, while, in vivo, they fit into a $1 \mu \mathrm{m}$ nucleolar region, leading to a compression factor of $1400 .{ }^{8}$ In vivo DNA compaction is achieved by histone proteins neutralizing approximately $57 \%$ of the negatively charged and positively charged ions and chemical structures present in

(4) Kepka, C.; Rhodin, J.; Gustavsson, P.-E.; Lemmens, R.; Tjerneld, F. In Purification of plasmid DNA in polymer/polymer aqueous two-phase systems. ESBES-4 "Life: Science and Technology", Proceedings of the 4th European Symposium on Biochemical Engineering Science, Delft, The Netherlands, august 28-30, 2002.

(5) Frerix, A.; Müller, M.; Kula, M. R.; Hubbuch, J. Scalable recovery of plasmid DNA based on aqueous two-phase separation. Biotechnol. Appl. Biochem. 2005, 42, 57-66.

(6) Ribeiro, S. C.; Monteiro, G. A . Cabral, J. M. S · Prazeres, D. M. F. Isolation of plasmid DNA from cell lysates by aqueous two-phase systems. Biotechnol. Bioeng. 2002, 78 (4), 376-384.

(7) Pettijohn, D. A Study of DNA, Partially Denatured DNA and ProteinDNA Complexes in Polyethyleneglycol-Dextran Phase System. Eur. J. Biochem. 1967, 3 (1), 25-32.

(8) Bloomfield, V. A. DNA condensation by multivalent cations. Biopolymers 1997, 44 (3), 269-282. 
the cell fluid. ${ }^{9}$ In vitro compaction of DNA can be induced by a variety of condensing agents. Mechanistically, two different groups can be identified, namely, condensing agents, which decrease repulsion between DNA segments or reduce DNA solvent interactions. ${ }^{8}$ In aqueous solutions, condensation by neutralizing phosphate charges requires at least cations of charge $3+$ or higher, such as spermidin $(3+)$ or spermin $(4+)$. In this case, over $90 \%$ of DNA charges have to be neutralized for condensation. ${ }^{10}$ Neutral polymers such as PEG at high concentrations and in the presence of adequate concentrations of salt also provoke condensations by making solvent-DNA interactions less favorable. This effect is also exploited for precipitation of nucleic acids. DNA in this condensed state in which the transition is induced by polymer and salt is called psi DNA. While the majority of studies on coil-globule transitions have been carried out using large T4 DNA, only few studies so far demonstrate the ability of pDNA to undergo coil-globule transition using techniques such as fluorescent correlation spectroscopy (FCS), ${ }^{11}$ atomic force microscopy (AFM) ${ }^{12}$ fluorescence resonance energy transfer (FRET),${ }^{13}$ or dye exclusion titration. ${ }^{13}$

In the current study, we thus examine the interplay of two polymeric systems; a two-phase system based on PEG and potassium phosphate sets the boundary conditions or parameter space. Within this system, the coil-globule behavior of pDNA (forming the second polymeric system) in the respective phases and its influence on the partitioning behavior is examined. The investigated parameters are PEG molecular weight, concentration, salt concentration, temperature, and $\mathrm{pH}$.

\section{Materials and Methods}

Potassium Phosphate. 50\% w/w stock solutions of different dipotassium hydrogen phosphate $\left(\mathrm{K}_{2} \mathrm{HPO}_{4}\right)$ and potassium dihydrogen phosphate $\left(\mathrm{KH}_{2} \mathrm{PO}_{4}\right)$ (from Merck, Darmstadt, Germany) mixtures were made in order to obtain the desired $\mathrm{pH}$.

PEG. PEG $\mathrm{MW}_{600}$ (MW distribution: 570-630) and $\mathrm{PEG}_{\mathrm{MW} 1000}$ (MW distribution: 950-1050) were purchased from Fluka (Buchs, Switzerland). To mimic intermediate states, PEG mixtures of $\mathrm{PEG}_{\mathrm{MW} 600}$ and $\mathrm{PEG}_{\mathrm{MW} 1000}$ were prepared using following equation:

$$
\begin{gathered}
\% \mathrm{PEG}_{\mathrm{MW} 600}=\frac{150000}{\mathrm{PEG}_{\mathrm{MW}}}-150 \\
\% \mathrm{PEG}_{\mathrm{MW} 1000}=100-\% \mathrm{PEG}_{\mathrm{MW} 600}
\end{gathered}
$$

where $\mathrm{PEG}_{\mathrm{MW}}$ represents the average molecular weight in terms of the hydroxyl group content of a PEG preparation that has been blended by a mixture of $\mathrm{PEG}_{\mathrm{MW} 600}$ and $\mathrm{PEG}_{\mathrm{MW} 1000}$.

Sodium chloride and potassium chloride of analytical grade were from Merck (Darmstadt, Germany); plasmid pCMV $\beta$ and RNA from E. coli were supplied by QIAGEN (Hilden, Germany). The starting state of the pDNA preparation was estimated by sodium dodecyl

(9) Zinchenko, A. A.; Sergeyev, V. G.; Yamabe, K.; Murata, S.; Yoshikawa, K. DNA compaction by divalent cations: Structural specificity revealed by the potentiality of designed quaternary diammonium salts. ChemBioChem 2004, 5 (3), 360-368.

(10) Arscott, P. G.; Ma, C. L.; Wenner, J. R.; Bloomfield, V. A. DNA condensation by cobalt hexaammine(III) in alcohol-water mixtures - Dielectricconstant and other solvent effects. Biopolymers 1995, 36 (3), 345-364.

(11) Kral, T.; Langner, M.; Benes, M.; Baczynska, D.; Ugorski, M.; Hof, M. The application of fluorescence correlation spectroscopy in detecting DNA condensation. Biophys. Chem. 2002, 95, 135-144.

(12) Wolfert, M. A.; Schacht, E. H., Toncheva, V.; Ulbrich, K.; Nazarova, O.; Seymour, L. W. Characterization of vectors for gene therapy formed by selfassembly of DNA with synthetic block copolymers. Hum. Gene Ther. 1996, 7, 2123-2133.

(13) Itaka, K.; Kyosuke, Y.; Harada, A.; Nakamura, K.; Kawaguchi, H.; Kataoka, K. Polyion complex micelles from plasmid DNA and poly(ethylene glycol)poly(L-lysine) block copolymer as serum-tolerable polyplex system: physiochemical properties of micelles relevant to gene transfection efficiency. Biomaterials 2003, 24, 4495-4506.
Table 1. Refractive Index (RI) and Dynamic Viscosity $(\eta)$ of Top and Bottom Phases (15\% $\mathrm{PEG}_{\mathrm{Mw} 800,} 20 \% \mathrm{KH}_{2} \mathrm{PO}_{4} /$ $\mathrm{K}_{2} \mathrm{HPO}_{4}$ ) Measured at $20{ }^{\circ} \mathrm{C}$

\begin{tabular}{lcc}
\hline & RI & $\eta$ \\
\hline top phase & 1.395 & $10.9 \mathrm{mPa} \mathrm{s}$ \\
bottom phase & 1.375 & $2.4 \mathrm{mPa} \mathrm{s}$
\end{tabular}

sulfate polyacrylamide gel electrophoresis (SDS-PAGE) and showed an approximate supercoiled fraction of $>80 \%$.

Preparation of the ATPS Extraction Systems. PEG stock solution as well as phosphate buffer of desired composition, nucleic acids, and water were weighted into graduated $1.5 \mathrm{~mL}$ tubes so that each system contained $30 \mu \mathrm{g}$ pDNA and $30 \mu \mathrm{g}$ RNA. After short vortex mixing for $\sim 5 \mathrm{~s}$, the samples were incubated at the desired temperature for $10 \mathrm{~min}$, repeatedly vortexed, and then centrifuged for $5 \mathrm{~min}$ at $1500 \mathrm{~g}$ at incubation temperature. The volumes of the top and bottom phases were noted, and samples of both phases were taken and analyzed immediately using the described highperformance liquid chromatography (HPLC) method.

HPLC. Analytical HPLC was performed using an HIC Source PHE column (Amersham, Freiburg, Germany) on an HP 1090 (Agilent, Waldbronn, Germany) on the basis of a method described by Diogo. ${ }^{14}$ Plasmids and RNA were quantified by injecting a 25 $\mu \mathrm{L}$ sample onto the HPLC column at $0.8 \mathrm{~mL} / \mathrm{min}$ at high salt and eluting with decreasing salt. The column was loaded at $1.5 \mathrm{M}\left(\mathrm{NH}_{4}\right)_{2}-$ $\mathrm{SO}_{4}$ in $10 \mathrm{mM}$ Tris/Cl at $\mathrm{pH} 8.0$, and, after keeping high salt conditions for $2 \mathrm{~min}$, a linear gradient to $10 \mathrm{mM}$ Tris $/ \mathrm{Cl}$ for $0.5 \mathrm{~min}$ at $\mathrm{pH} 8.0$ was performed and kept until RNA eluted completely. All absorbance readings were taken at $260 \mathrm{~nm}$. Quantitative results were obtained using a linear calibration of pDNA and RNA.

Phase Diagram. The binodal of the PEG 800/potassium phosphate system was determined using the titration method described by Albertsson. ${ }^{15}$ For identification of tie-lines, the phosphate concentrations of the top and bottom phases were determined using the Nanocolor phosphate test (Macherey-Nagel, Düren, Germany), and PEG concentrations were calculated from dry mass subtracting the salt fraction. Concentrations of potassium cations were quantitated using the flame emission spectrometer ELEX 6361 (Eppendorf, Hamburg, Germany).

Dynamic Light Scattering (DLS). The hydrodynamic radii of pDNA and its agglomerates were measured using the DynaPro DLS system (Wyatt Technology Corp., Santa Barbara, CA) with Dynamics V6 software. Prior to sample preparation, all solutions were centrifuged for $10 \mathrm{~min}$ at $15000 \mathrm{~g}$ in order to remove small particles and dust. The light scattering was performed with $20 \%$ laser power for 10 seconds per analysis and for a total of 10 replicates per sample. All measurements were performed using $45 \mu \mathrm{L}$ cuvettes. Since the deviation of viscosity and refractive index of both the top and the bottom phase did not change significantly within the applied temperature range, we used fixed parameters, which were required by the software for calculation of the hydrodynamic radius (Table 1).

Precipitation Experiments. The agglomeration of pDNA in PEG/ salt solutions was quantitatively monitored by performing precipitation experiments. Required amounts of PEG and salt stock solutions, together with deionized water and pDNA stock solution, were added into $1.5 \mathrm{~mL}$ reaction tubes in order to get a total volume of $500 \mu \mathrm{L}$ with $60 \mu \mathrm{g} / \mathrm{mL}$ of pDNA. Each tube was vortexed for $5 \mathrm{~s}$ immediately after preparation and then incubated for $10 \mathrm{~min}$ (at $20{ }^{\circ} \mathrm{C}$, if not otherwise stated). To separate the precipitates, the samples were centrifuged for $5 \mathrm{~min}$ at $15000 \mathrm{~g}$ in a $5180 \mathrm{R}$ Eppendorf centrifuge (Hamburg, Germany) at incubation temperature. Finally, the pDNA concentration in the supernatant of each sample was analyzed using HPLC, and the percentage of pDNA in the supernatant was calculated.

(14) Diogo, M. M.; Queiroz, J. A.; Prazeres, D. M. Assessment of purity and quantification of plasmid DNA in process solutions using high-performance hydrophobic interaction chromatography. J. Chromatogr., A 2003, 998 (1-2), $109-117$.

(15) Albertson, P.-A. Partition of Cell Particles and Macromolecules; Wiley: New York, 1985; Vol. 3. 


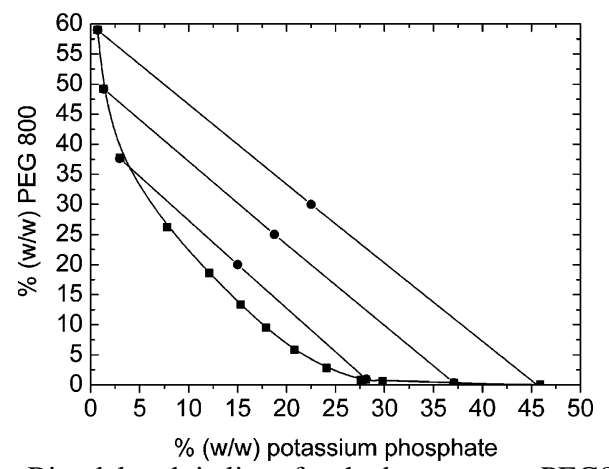

Figure 1. Binodal and tie lines for the base system PEG800/ $\mathrm{KH}_{2-}$ $\mathrm{PO}_{4} / \mathrm{K}_{2} \mathrm{HPO}_{4}$.

\section{Results}

It is well-known that the partitioning of solutes during twophase extraction (here, PEG/salt systems) is largely determined
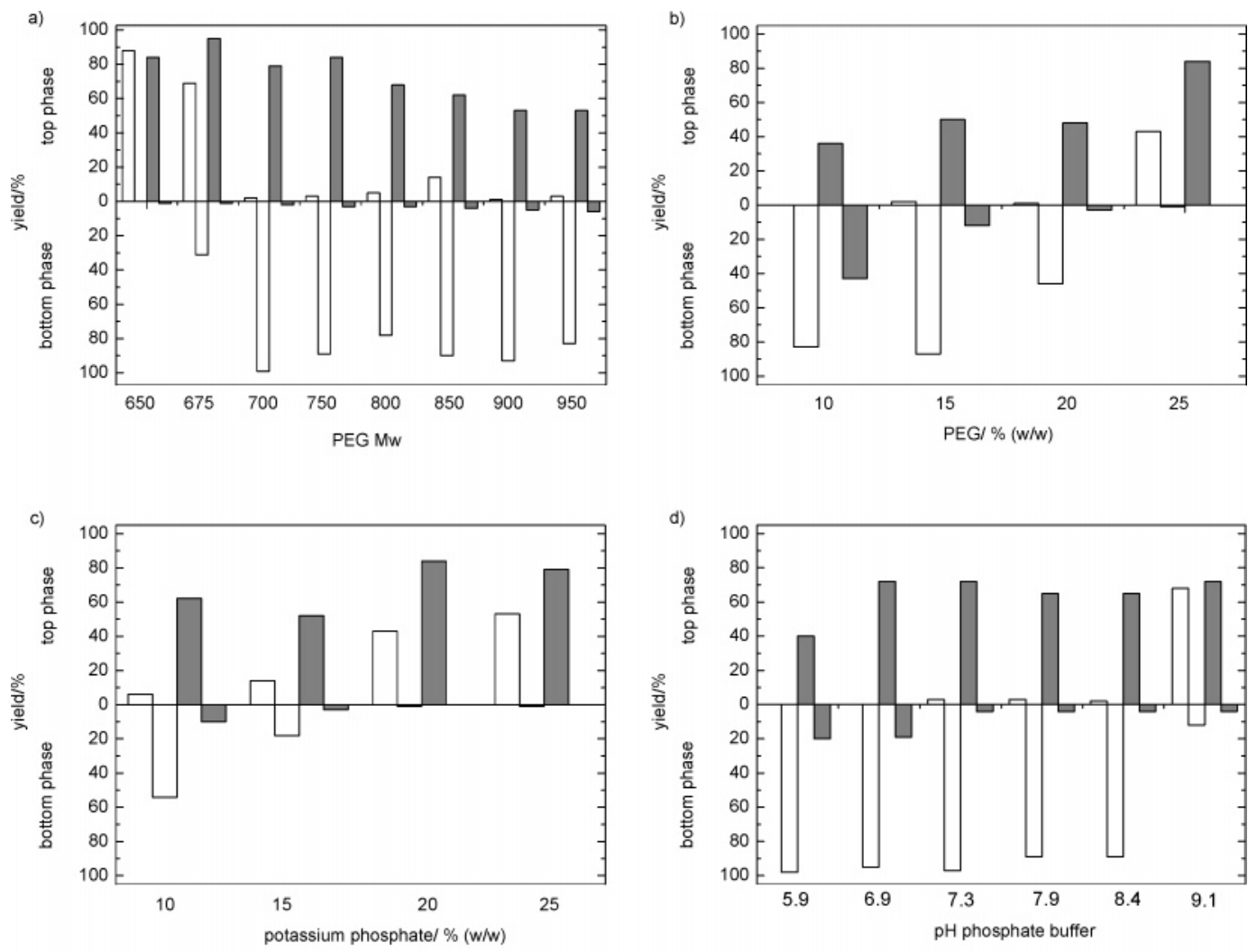

by the type and concentration of the phase-forming salt, the temperature, the $\mathrm{pH},[\mathrm{PEG}]$, and $\mathrm{PEG}_{\mathrm{MW}}$. The same parameters, however, play an important role when structural changes of DNA are induced by solution properties. ${ }^{8,16}$ The ATPSs investigated in the following section are based on a PEG- $\mathrm{KH}_{2} \mathrm{PO}_{4} / \mathrm{K}_{2} \mathrm{HPO}_{4}$ system (see Figure 1). If not stated otherwise, the base system parameters are $[\mathrm{PEG}]_{\mathrm{ATPS}} 15 \% \mathrm{w} / \mathrm{w} ; \mathrm{PEG}_{\mathrm{MW} 800}$; and $\left[\mathrm{KH}_{2} \mathrm{PO}_{4} /\right.$ and a temperature of $20^{\circ} \mathrm{C}$. As demonstrated below, the change to a formation of an interphase containing precipitated pDNA or RNA. It was found that the missing nucleic acid content for closing the mass balance over the top and bottom phases (Figure precipitated in the interphase (Figure 3).

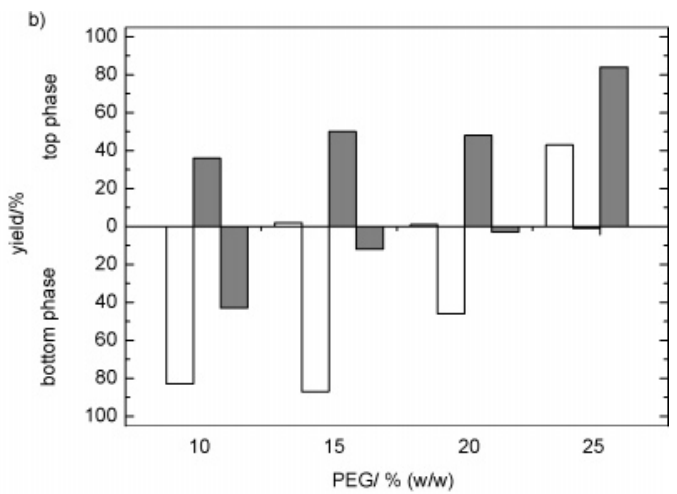

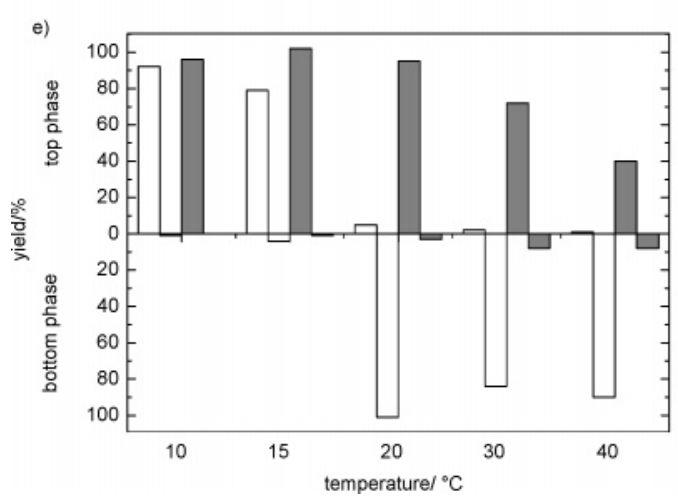
$\left.\mathrm{K}_{2} \mathrm{HPO}_{4}\right]_{\text {ATPS }} 20 \% \mathrm{w} / \mathrm{w}$, abbreviated as $(15 / 20)_{\text {ATPS }}^{800}$, at $\mathrm{pH} 7.4$ in partitioning behavior in the various systems is closely connected 2) of the respective systems corresponded to the fraction

Partitioning Behavior of pDNA and RNA. PEG Molecular Weight $-(15 / 20)_{A T P S}^{x}$. When analyzing the influence of $\mathrm{PEG}_{\mathrm{MW}}$

Figure 2. Influence of different parameters on pDNA and RNA partitioning using $1.5 \mathrm{~g}$ systems containing $30 \mu \mathrm{g}$ of pDNA and $30 \mu \mathrm{g}$ of RNA. (a) Variation in PEG MW (mixture); system: 15\% w/w PEG, 20\% potassium phosphate, pH 7.4. (b) Variation in PEG concentration; system: PEG 800, 20\% w/w potassium phosphate, $\mathrm{pH}$ 7.4. (c) Variation in potassium phosphate concentration; system: 25\% w/w PEG 800, $\mathrm{pH}$ 7.4. (d) Variation in the $\mathrm{pH}$ of potassium phosphate buffer; system: $15 \%$ PEG 800, $20 \%$ potassium phosphate. (e) Variation in temperature during extraction; system: $15 \%$ w/w PEG 800, 20 w/w potassium phosphate, pH 7.4. Key: pDNA = white bars; RNA = gray bars. Graphs $\mathrm{b}$ and $\mathrm{c}$ are reprinted with permission from A. Frerix, M. Müller, M. R. Kula, and J. Hubbuch, 2005, Biotechnology and Applied Biochemistry 42, 57-66. (C) Portland Press Ltd. 

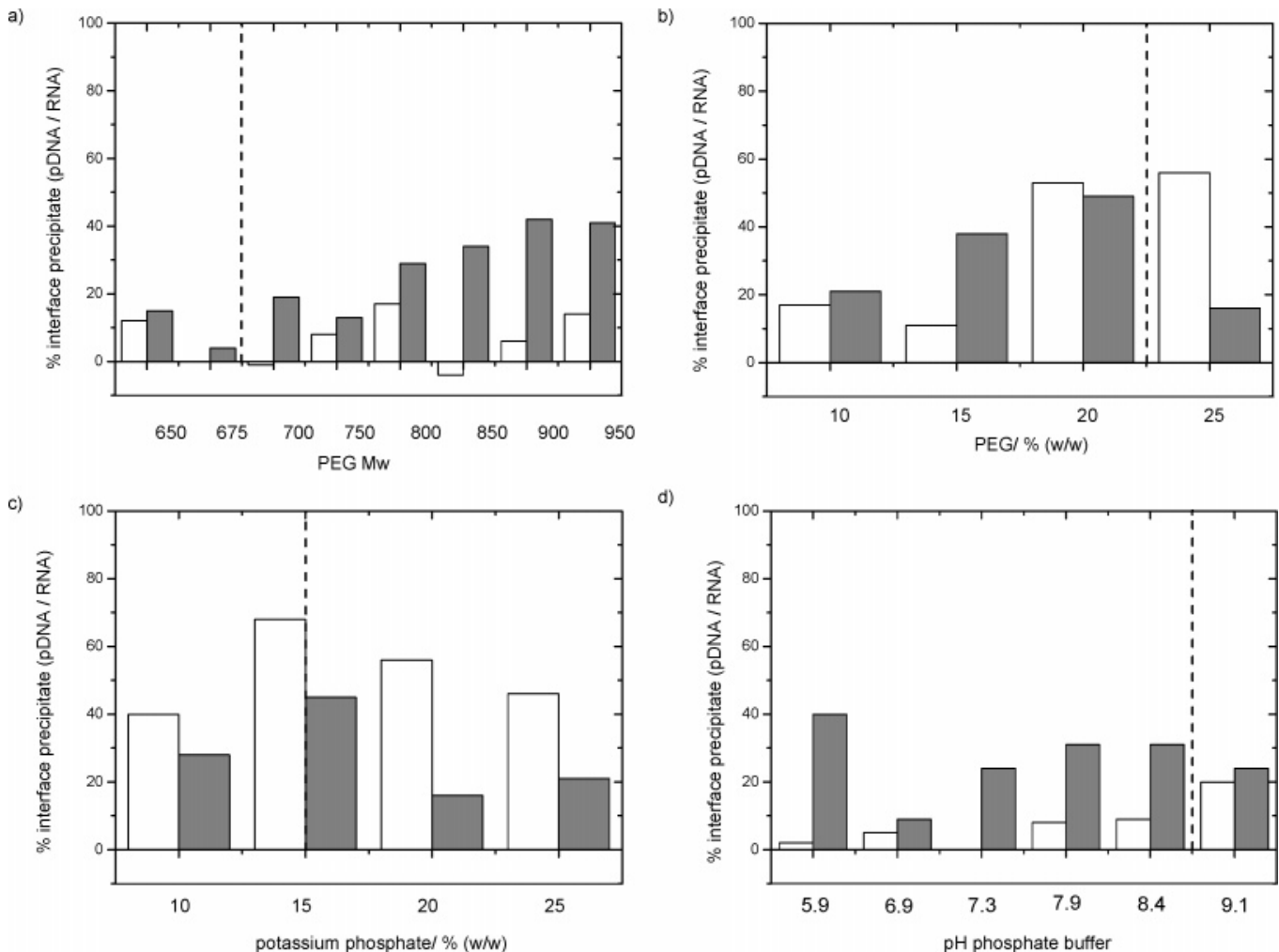

d)
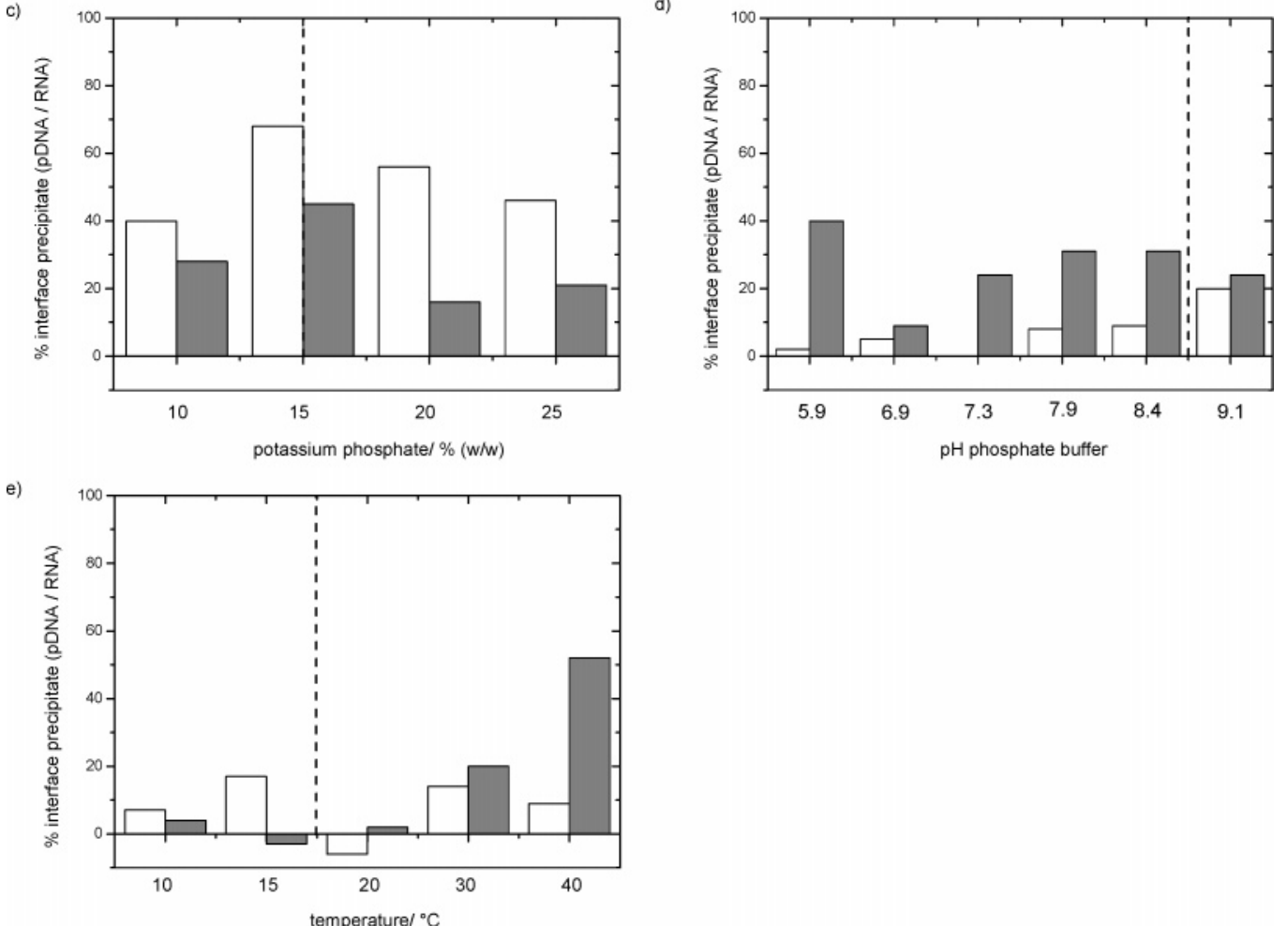

Figure 3. Fraction of pDNA/RNA precipitated at the interphase using $1.5 \mathrm{~g}$ systems containing $30 \mu \mathrm{g}$ of pDNA and $30 \mu \mathrm{g}$ of RNA. (a) Variation in PEG MW (mixture); system: 15\% w/w PEG, 20\% potassium phosphate, pH 7.4. (b) Variation in PEG concentration; system: PEG 800, 20\% w/w potassium phosphate, $\mathrm{pH}$ 7.4. (c) Variation in potassium phosphate concentration; system: $25 \% \mathrm{w} / \mathrm{w}$ PEG 800 , $\mathrm{pH} 7.4$. (d) Variation in the $\mathrm{pH}$ of potassium phosphate buffer; system: $15 \%$ PEG 800, 20\% potassium phosphate. (e) Variation in temperature during extraction; system: $15 \%$ w/w PEG 800, $20 \mathrm{w} / \mathrm{w}$ potassium phosphate, $\mathrm{pH}$ 7.4. Key: pDNA = white bars; RNA = gray bars; change in partitioning behavior (Figure 2) $=$ dashed line. Graphs b and c are reprinted with permission from A. Frerix, M. Müller, M. R. Kula, and J. Hubbuch, 2005, Biotechnology and Applied Biochemistry, 42, 57-66. (c) Portland Press Ltd.

( $\mathrm{PEG}_{\mathrm{MW} 600} / \mathrm{PEG}_{\mathrm{MW} 1000}$ mixing ratio) on nucleic acid partitioning, a drastic change in respect to the partitioning behavior of pDNA could be discovered (Figure 2a). At $\mathrm{PEG}_{\mathrm{MW} 650}$, over $80 \%$ of both RNA and pDNA are found in the top phase. Between $\mathrm{PEG}_{\mathrm{MW} 650}$ and $\mathrm{PEG}_{\mathrm{MW} 700}$, a drastic change of the partitioning coefficient occurs, and pDNA is located almost entirely in the bottom phase. The difference in the PEG mixing ratio between $\mathrm{PEG}_{\mathrm{MW} 650}$ and $\mathrm{PEG}_{\mathrm{MW} 700}$ leading to this drastic behavior is given by a decrease in the fraction of $\mathrm{PEG}_{\mathrm{MW} 600}$ from $80 \%$ to $65 \%$ (eq 1). A further increase in the average molecular weight of the PEG mixture to $\mathrm{PEG}_{\mathrm{MW} 950}$ leads to a continuous increase in the precipitated RNA fraction to $40 \%$ at $\mathrm{PEG}_{\mathrm{MW} 950}$ located at the interface. A comparable trend for pDNA is not detected (Figure 3a).

PEG Concentration - $(x / 20)_{\text {ATPS }}^{800}$. The partitioning behavior of pDNA and RNA as a function of [PEG] $]_{\text {ATPS }}$ can be seen in Figure $2 \mathrm{~b}$ (taken from ref 5; reprinted with permission). At a $[\mathrm{PEG}]_{\mathrm{ATPS}}$ of $10-15 \% \mathrm{w} / \mathrm{w}$, over $80 \%$ of the pDNA is found in the bottom phase. When the $[\mathrm{PEG}]_{\mathrm{ATPS}}$ is further increased to $20 \% \mathrm{w} / \mathrm{w}$, pDNA is still found in the bottom phase; however, a drop in the soluble fraction to approximately $50 \%$ occurs (Figure $3 b)$. This fraction of soluble pDNA did not change significantly with a further increase in $[\mathrm{PEG}]_{\mathrm{ATPS}}$ to $25 \% \mathrm{w} / \mathrm{w}$; however, pDNA partitioned to the top phase. RNA is found initially, at $10 \%[\mathrm{PEG}]_{\mathrm{ATPS}}$, equally distributed in the top and bottom phases. With increasing $[\mathrm{PEG}]_{\mathrm{ATPS}}$, RNA concentration in the top phase remains stable (except for a $[\mathrm{PEG}]_{\mathrm{ATPS}}$ of $25 \%$ ), while the concentration of soluble RNA in the bottom phase decreased almost quantitatively.

Potassium Phosphate Concentration - $(25 / x)_{A T P S}^{800}$. The dependence of pDNA partitioning on potassium phosphate concentration is given in Figure $2 \mathrm{c}$ (taken from ref 5). At a $\left[\mathrm{KH}_{2} \mathrm{PO}_{4} /\right.$ $\left.\mathrm{K}_{2} \mathrm{HPO}_{4}\right]_{\text {ATPS }}$ of $10 \% \mathrm{w} / \mathrm{w}$, approximately $50 \%$ of the pDNA is found in the bottom phase, while only traces are found in the top phase. When the concentration is increased to $15 \% \mathrm{w} / \mathrm{w}$, the fraction of soluble pDNA is reduced to only $30 \%$ equally 


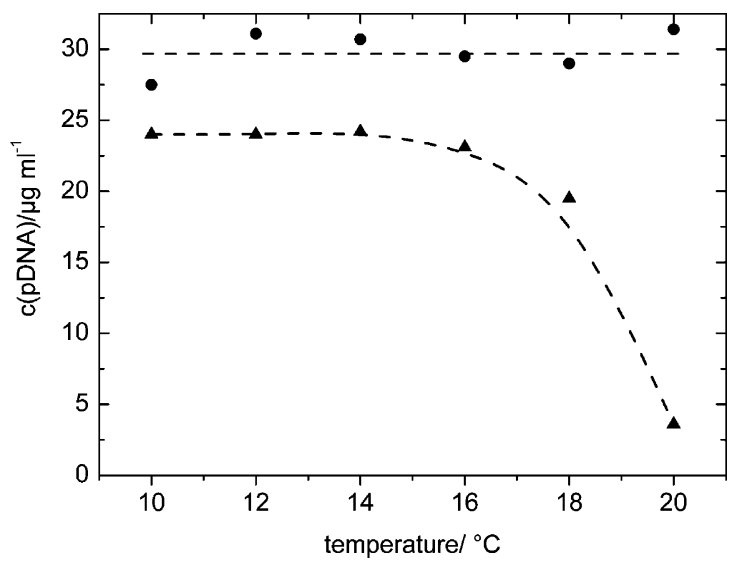

Figure 4. pDNA concentration in the supernatant of the top or bottom phase as a function of temperature (initially pDNA was extracted to the top phase at $10^{\circ} \mathrm{C}$ or to the bottom phase at $20^{\circ} \mathrm{C}$ ). (๑) pDNA concentration in bottom phase; $(\boldsymbol{\Delta})$ pDNA concentration in top phase.

distributed to both phases. With a further increase to 20 and $25 \%$ $\mathrm{w} / \mathrm{w}$, the solubility in the top phase increases to a final value of $50 \%$, while the bottom phase is depleted of pDNA. Over the range of concentration analyzed, the amount of precipitated RNA varied between 16 and 45\%; however, no trend could be observed (Figure 3c).

Effect of $p H-(15 / 20)_{A T P S}^{800}$. Between $\mathrm{pH} 5.9$ and 8.4, almost $90 \%$ of the pDNA was found in the bottom phase (Figure $2 \mathrm{~d}$ ), while the yield of RNA in the top phase increased from 40 to $70 \%$ between pH 5.9 and 6.9 and then remained constant.

A further increase in $\mathrm{pH}$ from 8.4 to 9.1 led to a drastic reduction in pDNA yield in bottom phase from 89 to $12 \%$ and to an increase in that of the top phase from 2 to $68 \%$. It has to be noted that a change in the $\mathrm{pH}$ by a change in the buffer composition consequently results in a change in molar concentration of $\left[\mathrm{K}^{+}\right]$ and $\left[\mathrm{PO}_{4}{ }^{3-}\right]$.

Effect of Temperature - $(15 / 20)_{A T P S}^{800}$. The effect of temperature was investigated by performing partitioning and extractions at individual temperatures in the range between 10 and $40^{\circ} \mathrm{C}$ (Figure 2e). While pDNA partitioned into the top phase for temperatures lower than $15^{\circ} \mathrm{C}$, a shift into the bottom phase occurred for temperatures equal to or higher than $20^{\circ} \mathrm{C}$. A trend in overall system solubility cannot be detected (Figure 3e). In contrast, RNA showed a behavior similar to that described above when $\mathrm{PEG}_{\mathrm{MW}}$ is increased, namely, an increased precipitation on the interphase with an increase of temperature. Over the temperature range investigated, RNA solubility in the top phase decreased from almost 100 to $50 \%$ (Figure 3e).

The latter indicates that the solubility of the respective nucleic acid forms in the polymer-rich phase might play an important role. We thus prepared a two-phase system at $10{ }^{\circ} \mathrm{C}$, where pDNA has been shown to quantitatively partition into the top phase, and divided the obtained top phase into several aliquots. These aliquots were then set to different temperatures covering the range between 10 and $20^{\circ} \mathrm{C}$. After centrifugation at $15000 \mathrm{~g}$ for $5 \mathrm{~min}$ at the corresponding temperature, the pDNA concentration in the supernatant was quantified. As expected, pDNA concentration has not been affected in the temperature range between 10 and $17{ }^{\circ} \mathrm{C}$; however, above $17^{\circ} \mathrm{C}$, a drastic reduction in the pDNA concentration in the supernatant was observed (Figure 4). This corresponds to the partitioning behavior shown in Figure 2e. An analogous experiment with pDNA extracted to the bottom phase showed no influence of temperature onto pDNA solubility (Figure 4).
Table 2. [PEG], $\left[\mathrm{PO}_{4}{ }^{3-}\right]$, and $\left[\mathrm{K}^{+}\right]$of the Two-Phase System Used for Partitioning Study ${ }^{a}$

\begin{tabular}{|c|c|c|c|c|c|}
\hline \multicolumn{2}{|c|}{ total composition } & \multicolumn{2}{|c|}{ top phase } & \multicolumn{2}{|c|}{ bottom phase } \\
\hline [PEG] & [K $\mathrm{K}^{-}$phosphate] & [PEG] & {$[\mathrm{K}+]$} & [PEG] & {$[\mathrm{K}+]$} \\
\hline$\% \mathrm{w} / \mathrm{w}$ & $\% \mathrm{w} / \mathrm{w}$ & $\% \mathrm{w} / \mathrm{w}$ & $\mathrm{mM}$ & $\% \mathrm{w} / \mathrm{w}$ & $\mathrm{mM}$ \\
\hline 10 & 20 & 31 & 470 & 2 & 3450 \\
\hline 15 & 20 & 41 & 325 & 1 & 3900 \\
\hline 20 & 20 & 45 & 245 & 0.5 & 4750 \\
\hline 25 & 20 & 51 & 205 & 0.5 & 5550 \\
\hline 25 & 10 & 31 & 500 & 2 & 3350 \\
\hline 25 & 15 & 42.5 & 305 & 0.5 & 4400 \\
\hline 25 & 20 & 51 & 205 & 0.5 & 5600 \\
\hline 25 & 25 & 56 & 135 & 0.2 & 6900 \\
\hline
\end{tabular}

${ }^{a}$ The [PEG]s in the respective phases correspond to the binodal line concentrations shown in Figure 1. The $\left[\mathrm{K}^{+}\right]$s were analyzed using flame emission spectroscopy.

Solubility of pDNA. To more closely examine the effect of the different system parameters on pDNA solubility independently from the formation of a two-phase system, the salt component was altered from potassium phosphate to potassium chloride or sodium chloride. The concentrations used were chosen to approximately cover the range of molar compositions of $\left[\mathrm{K}^{+}\right]_{\mathrm{tp}}$ and $[\mathrm{PEG}]_{\mathrm{tp}}$ in the top phase (tp) of the various ATPSs. Table 2 lists the compositions of the top and bottom phases described above. Depending on the respective system, the molarity of $\left[\mathrm{K}^{+}\right]_{\mathrm{tp} / \mathrm{bp}}$ in the top and bottom phase (bp) varied between 135 and $500 \mathrm{mM}$ and 3350 and $6900 \mathrm{mM}$, respectively. The percentage of $[\mathrm{PEG}]_{\mathrm{tp} / \mathrm{bp}}$ varied accordingly between 31 and $56 \% \mathrm{w} / \mathrm{w}$ and 0.2 and $2 \% \mathrm{w} / \mathrm{w}$ in the top and bottom phases, respectively. The pDNA concentration was kept at $60 \mu \mathrm{g} / \mathrm{mL}$.

PEG Molecular Weight $-(41 / x)_{\text {Solubility. Figure 5a shows }}^{y}$ pDNA solubility as a function of $\mathrm{PEG}_{\mathrm{MW}}$ and a $\left[\mathrm{K}^{+}\right]$of 325 and $500 \mathrm{mM}$. While pDNA was almost quantitatively soluble at $\mathrm{PEG}_{\mathrm{MW} 600}$, a slight reduction in pDNA solubility for $325 \mathrm{mM}$ $\left[\mathrm{K}^{+}\right]$to $56 \%$ and a clearer reduction to approximately $20 \%$ for $500 \mathrm{mM}\left[\mathrm{K}^{+}\right]$could be observed for $\mathrm{PEG}_{\mathrm{MW} 800}$. When comparing the solubility found in this system with the partition change in Figure 2a, a qualitative agreement between the reduced solubility of the $\mathrm{PEG}_{\mathrm{MW} 650}$ and $\mathrm{PEG}_{\mathrm{MW} 700}$ systems from approximately 100 to $96 \%$ and 50 to $25 \%$ for $325 \mathrm{mM}$ and $500 \mathrm{mM}$, respectively, and the change in partitioning behavior seen in Figure $2 \mathrm{a}$ exists.

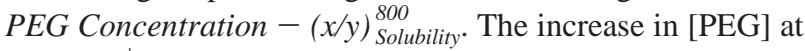
different $\left[\mathrm{K}^{+}\right]$concentrations led to a distinct decrease in solubility (Figure 5b). With a further increase in [PEG], this decrease could be reversed, and solubility is enhanced. The region of reduced solubility and thus the significance of the change in solubility behavior correlate to increasing $\left[\mathrm{K}^{+}\right]$. When comparing these solubility studies to the pDNA partitioning shown in Figure $2 b$, the general trend is mirrored. A very low solubility for the top phase composition of $[\mathrm{PEG}]_{\mathrm{tp}} 31 \% /\left[\mathrm{K}^{+}\right]_{\mathrm{tp}} 470 \mathrm{mM}$ corresponds to pDNA partitioning into the bottom phase, as seen for the $(10 / 20)_{\text {ATPS }}^{800}$ system. With an increase in $[$ PEG] tp to $41 \%$, considering the $(15 / 20)_{\text {ATPS system pDNA remains in the }}^{800}$ bottom phase, solubility, however, could be expected to lie in the range of $60-80 \%$ (Figure $5 \mathrm{~b}$ ). With a further increase to $45 \%$ and $51 \%$ in $[\mathrm{PEG}]_{\mathrm{tp}}$, a near complete pDNA solubility is given (Figure $5 \mathrm{~b}$ ), corresponding to partitioning into the top phase (Figure 2b). It has to be noted that with an increase in $[\mathrm{PEG}]_{\mathrm{tp}}$ from 31 to $51 \%$, a clear decrease in $\left[\mathrm{K}^{+}\right]_{\mathrm{tp}}$ from 470 to $205 \mathrm{mM}$ is experienced (Table 2).

$K^{+}$Concentration $-(x / y)_{\text {Solubility. The solubility of pDNA as }}^{800}$. The a function of $\left[\mathrm{K}^{+}\right]$is given in Figure $5 \mathrm{c}$ for [PEG] of 35 and $41 \%$.

(16) Yoshikawa, K. Controlling the higher-order structure of giant DNA molecules. Adv. Drug Delivery Rev. 2001, 52 (3), 235-244. 
a)

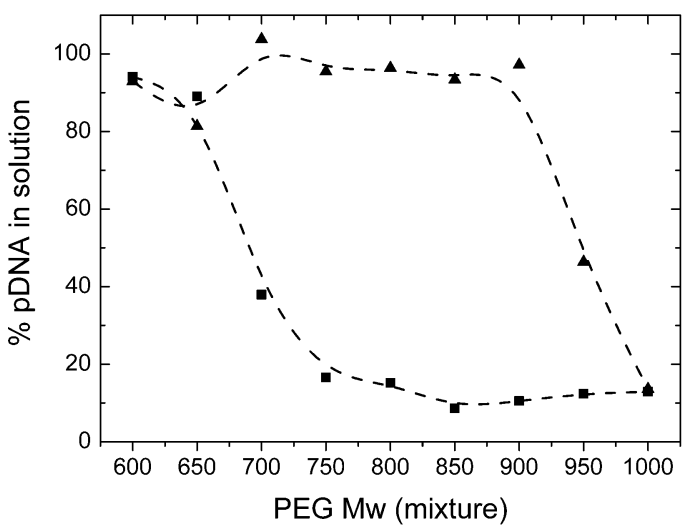

c)

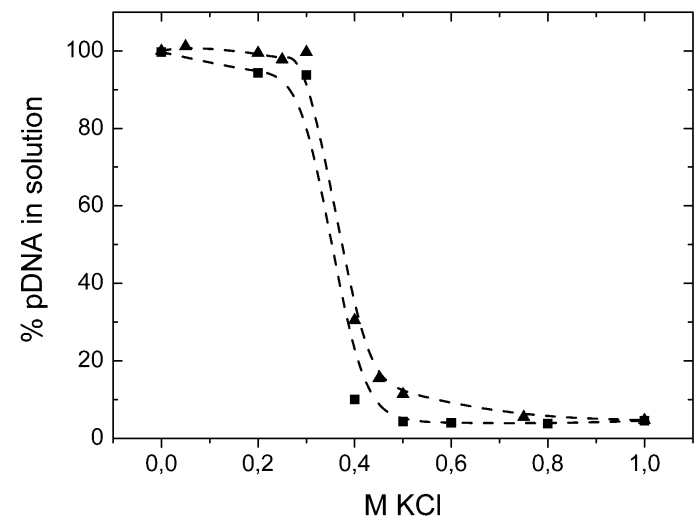

b)

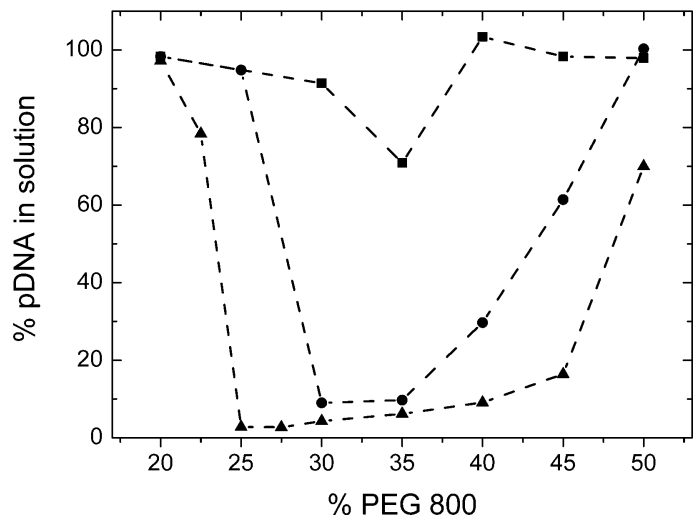

d)

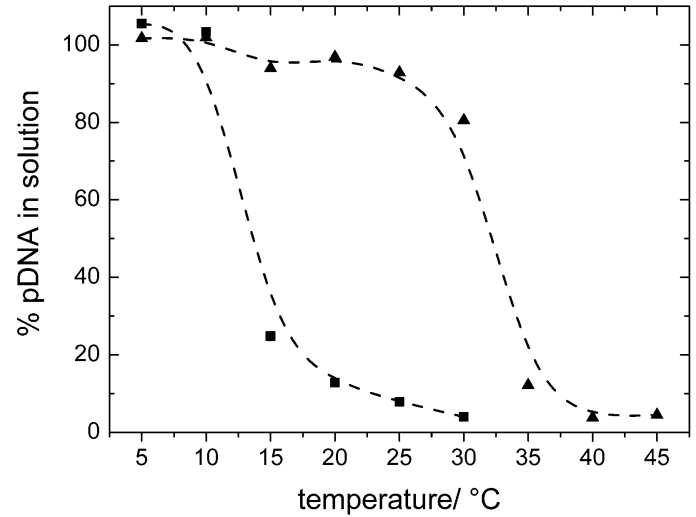

Figure 5. Precipitation of pDNA in solutions with PEG and $\mathrm{KCl}$; all samples contain $60 \mu \mathrm{g} / \mathrm{mL}$ of pDNA. (a) Influence of PEG molecular weight in solution with (A) $41 \%$ PEG, $0.325 \mathrm{M} \mathrm{KCl}$ or (ם) $41 \%$ PEG, $0.5 \mathrm{M} \mathrm{KCl}$. (b) Influence of PEG800 concentration in solutions with

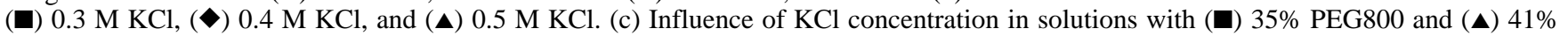
PEG800. (d) Influence on temperature in solution with (A) 41\% PEG, $0.325 \mathrm{M} \mathrm{KCl}$ or (ם) $41 \%$ PEG, $0.5 \mathrm{M} \mathrm{KCl}$.

For both [PEG]s, a sharp decrease in solubility between 300 and $500 \mathrm{mM}\left[\mathrm{K}^{+}\right]$is seen. The results indicate that a change in cation concentration introduces a greater influence on system properties than experienced with [PEG]. When these results are compared to the partitioning studies shown in Figure 2c, it shows that both systems with pDNA partitioning into the bottom phase- $(10 / 20)$ ${ }_{\text {ATPS }}^{800}$ and $(15 / 20)_{\text {ATPS }}^{800}$-lie within the unstable region where solubility drastically decreases. With an increase in phosphate concentration in the ATPS (Figure 2c), a decrease in $\left[\mathrm{K}^{+}\right]$in the top phase is experienced. With a further increase in [PEG] and thus a decrease in $\left[\mathrm{K}^{+}\right]$in the top phase, a retained solubility can be expected and reflects pDNA partitioning into the top phase. Within the parameter values examined in this study, the increase in [PEG] from 31 to $51 \%$ corresponds to the "resolvation" effect shown in Figure $5 \mathrm{~b}$ and is enhanced by a decrease in $\left[\mathrm{K}^{+}\right]$.

Temperature $-(41 / x)_{\text {Solubility. }}^{800}$ The effect of temperature on pDNA solubility at different $\left[\mathrm{K}^{+}\right]$can be seen in Figure $5 \mathrm{~d}$. A clear reduction in solubility between 10 and $15^{\circ} \mathrm{C}$ for $500 \mathrm{mM}$ $\left[\mathrm{K}^{+}\right]$could be observed, whereas, for $325 \mathrm{mM}\left[\mathrm{K}^{+}\right]$, no influence on solubility was found up to $25^{\circ} \mathrm{C}$. A further increase to $45^{\circ} \mathrm{C}$ then led to a drastic decrease in solubility. Again a qualitative correspondence to the partitioning behavior found in Figure 2e is given.

ATPS Solubility. Next to the specific solubilities in the top and bottom phases of the analyzed ATPS, a general trend with respect to the overall mass balance and thus the overall solubility can be seen (Figure $3 a-e$ ). While the switch from the top to the bottom phase in Figure 3a,d,e is accompanied by a high system solubility for pDNA, a clear change in this behavior is seen in
Figure 3b,c, where the change in partitioning behavior also results in a clear reduction in the overall system solubility.

PEG/NaCl Systems. As no direct measurement of the coilglobule transition could be carried out in this study, a direct comparison to systems used in other studies was performed. Thus, we used $\mathrm{NaCl}$ as a replacement for potassium phosphate to compare findings with pDNA to results by other groups providing a direct measurement of the coil-globule transition by examining the behavior of much larger T4 DNA.9,16-21

Solubility. Figure 6 shows pDNA solubility as a function of $\left[\mathrm{Na}^{+}\right]$for two different $\mathrm{PEG}_{\mathrm{MW}}$ and $[\mathrm{PEG}]$. The results qualitatively resemble the solubility behavior presented above and show a drastic decrease at a $\left[\mathrm{Na}^{+}\right]$of approximately 80 and $200 \mathrm{mM}$ for the $\mathrm{PEG}_{\mathrm{MW} 800}$ and $\mathrm{PEG}_{\mathrm{MW} 8000}$ systems, respectively. The critical $\left[\mathrm{Na}^{+}\right]$for the $\mathrm{PEG}_{\mathrm{MW} 800}$ system is thus $220 \mathrm{mM}$ lower than that observed with $\left[\mathrm{K}^{+}\right]$for identical [PEG].

Size Distribution. A direct measurement of pDNA conformation in an ATPS is hampered by the fact that DLS is extremely sensitive

(17) Melnikov, S. M.; Sergeyev, V. G.; Yoshikawa, K.; Takahashi, H.; Hatta, I. Cooperativity or phase transition? Unfolding transition of DNA cationic surfactant complex. J. Chem. Phys. 1997, 107 (17), 6917-6924.

(18) Minagawa, K.; Matsuzawa, Y.; Yoshikawa, K.; Khokhlov, A. R.; Doi, M. Direct observation of the coil-globule transition in DNA-molecules. Biopolymers 1994, 34 (4), 555-558.

(19) Murayama, H.; Yoshikawa, K. Thermodynamics of the collapsing phase transition in a single duplex DNA molecule. J. Phys. Chem. B 1999, 103 (47), 10517-10523.

(20) Zinchenko, A. A.; Yoshikawa, K. Na+ shows a markedly higher potential than $\mathrm{K}+$ in DNA compaction in a crowded environment. Biophys. J. 2005, 88 (6), 4118-4123.

(21) Vasilevskaya, V. V.; Khokhlov, A. R.; Matsuzawa, Y.; Yoshikawa, K. Collapse of single DNA molecule in poly(ethylene glycol) solutions. J. Chem. Phys. 1995, 102 (16), 6595-6602. 


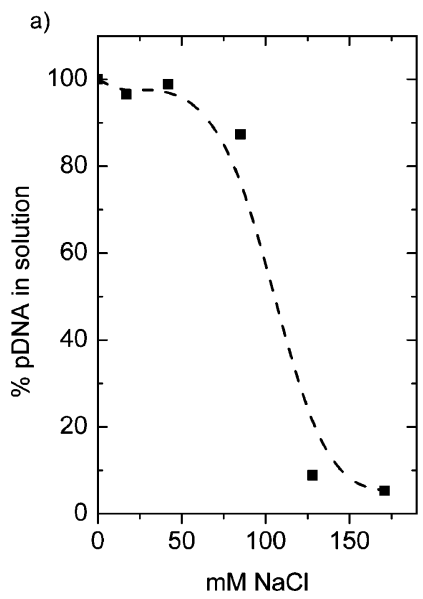

b)

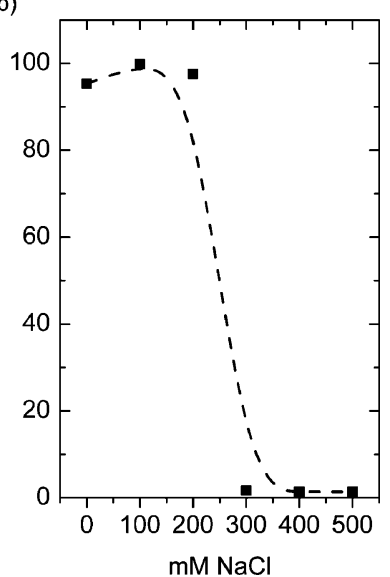

Figure 6. Dependence of pDNA solubility in PEG solutions on $\mathrm{NaCl}$ concentration: (a) $90 \mu \mathrm{g} / \mathrm{mL}$ of pDNA solved in $41 \%$ PEG800 and $0-1 \% \mathrm{w} / \mathrm{w} \mathrm{NaCl}$; (b) $90 \mu \mathrm{g} / \mathrm{mL}$ of pDNA solved in $100 \mathrm{mg} / \mathrm{mL}$ of PEG8000 and $0-0.5 \mathrm{M} \mathrm{NaCl}$.

to large particles or turbidity. A direct measurement of pDNA size distribution in ATPSs is thus quite difficult. Figure 7a shows the distribution of the hydrodynamic radii $\left(r_{\text {hyd }}\right)$ of pDNA determined by DLS as a function of the $\mathrm{NaCl}$ concentration. The [pDNA] was set to $100 \mu \mathrm{g} / \mathrm{mL}$, and $\mathrm{PEG}_{\mathrm{Mw} 800}$ was used at [PEG] $=41 \%$. For $\mathrm{NaCl}$ concentrations below $50 \mathrm{mM}$, an average $r_{\text {hyd }}$ in the range of $60-70 \mathrm{~nm}$ was determined, whereas, at $85 \mathrm{mM}$, the radius increased slightly to $r_{\mathrm{h}} \sim 100 \mathrm{~nm}$. Higher $\mathrm{NaCl}$ concentrations, solution properties at which an extreme reduction of solubility occurs, resulted in drastically larger radii of $r_{\mathrm{h}}>$ $500 \mathrm{~nm}$ with an extremely broad distribution. The effect of [pDNA] on this increase in $r_{\text {hyd }}$ connected to a loss of solubility is shown in Figure 7b. With a decrease in [pDNA] from 50 to $0.25 \mu \mathrm{g} / \mathrm{mL}$, a clear reduction in the resulting $r_{\text {hyd }}$ is seen. The measured $r_{\text {hyd }}$ at low [pDNA] but relatively high $[\mathrm{NaCl}]$ is still significantly higher than $r_{\text {hyd }}$ measured for pDNA at low $[\mathrm{NaCl}]$.

\section{Discussion}

The psi condensation of DNA can be attributed to a thermodynamically unfavorable contact between "stiff" DNA and "flexible" PEG, which decreases the available free space for coil-structured DNA in solution, leading to a decrease in the solvent quality for DNA. At a critical value of system parameters such as [PEG], [salt], temperature, or $\mathrm{pH}$ in solution, this reduced solvent quality induces a collapse transition of DNA into a globule conformation. It has been shown that these critical values leading to DNA collapse can be described by the minimum free energy of DNA and external solution. ${ }^{21,22}$ In this approach, the free energy of mixing is described by the classical Flory-Huggins approach, which also forms the principle framework for describing phase separation and partitioning in ATPSs. ${ }^{20}$ In the following section, the experimental results described above are set in relation to the literature data and discussed under the assumption that the system parameters of the applied ATPS induce a coil-globule transition of pDNA, leading to a distinct change in its partitioning behavior in the respective ATPS.

PEG-NaCl Systems. Traditionally, the coil-globule transition was directly visualized employing fluorescence microscopy for the detection of 4',6-diamidino-2-phenylindole (DAPI)-labeled T4 DNA (166 kbp) and has been studied by several research

(22) Kleideiter, G.; Nordmeier, E. Poly(ethylene glycol)-induced DNA condensation in aqueous/methanol containing low-molecular-weight electrolyte solutions Part I. Theoretical considerations. Polymer 1999, 40 (14), 4013-4023. a)

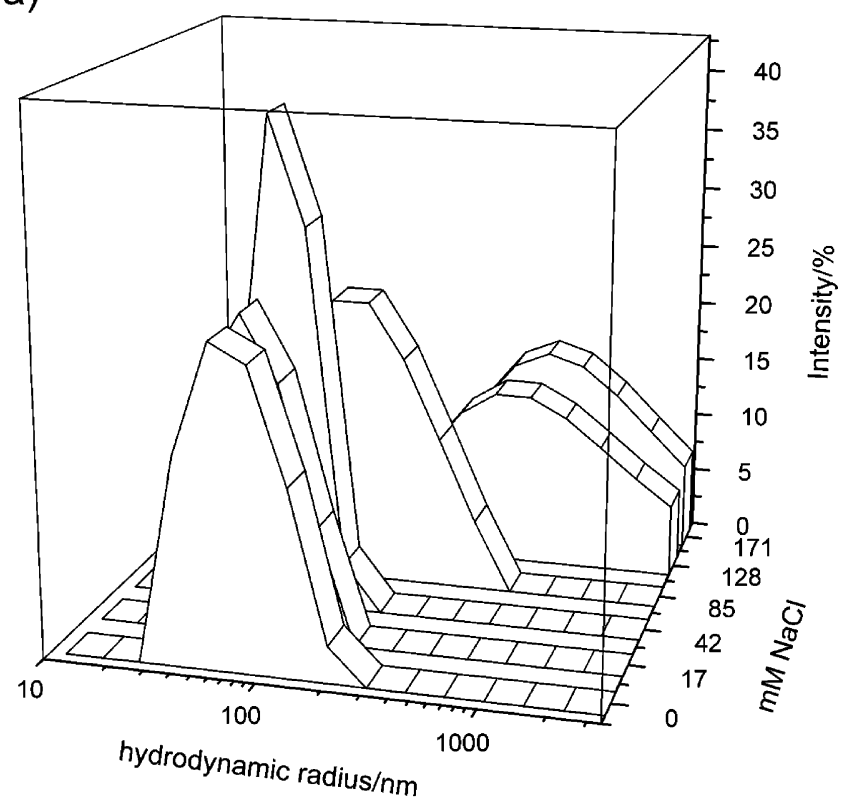

b)

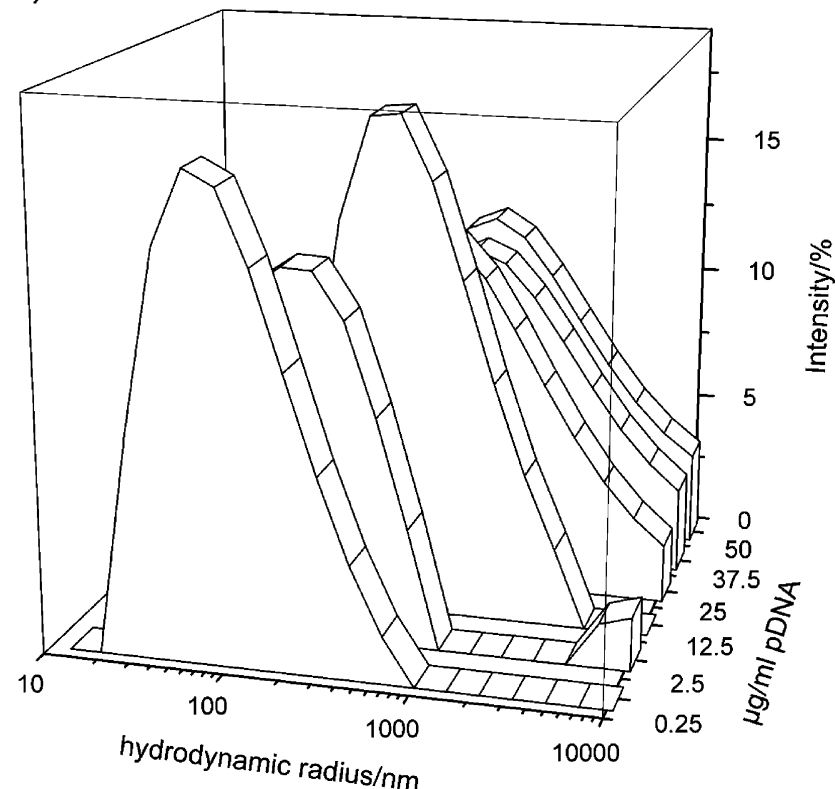

Figure 7. (a) Particle size distribution of pDNA and its agglomerates as a function of $\mathrm{NaCl}$ concentration measured with DLS; samples prepared with $41 \%$ PEG800, $100 \mu \mathrm{g} / \mathrm{mL}$ of pDNA, and $0-0.5 \mathrm{M}$ $\mathrm{NaCl}$. (b) Plot of particle size distribution of pDNA agglomerates in globule state as a function of pDNA concentration; samples prepared with $41 \%$ PEG800, $140 \mathrm{mM} \mathrm{NaCl}$, and $0.25-50 \mu \mathrm{g} / \mathrm{mL}$ of pDNA.

groups $^{16,18,19,21,24}$ The resolution of this method, however, is limited and proved to be insufficient for the plasmid used in this study (pCMV $\beta$ : $6.7 \mathrm{kbp}$ ). In the work of Vasilevskaya et al., ${ }^{21}$ the coil-globule transition of T4 DNA was observed at a $\mathrm{NaCl}$ concentration of $0.2 \mathrm{M}$ and a polymerization degree of $P=200$, corresponding to a $\mathrm{PEG}_{\mathrm{MW}}$ of approximately 8000 . Even though different DNA structures and sizes were used in the present

(23) Johansson, H. O.; Karlstrom, G.; Tjerneld, F.; Haynes, C. A. Driving forces for phase separation and partitioning in aqueous two-phase systems. $J$. Chromatogr., B 1998, 711 (1-2), 3-17.

(24) Yoshikawa, K.; Yoshikawa, Y.; Koyama, Y.; Kanbe, T. Highly effective compaction of long duplex DNA induced by polyethylene glycol with pendant amino groups. J. Am. Chem. Soc. 1997, 119 (28), 6473-6477. 
comparison, a similar value for the critical $\mathrm{NaCl}$ concentration causing a solubility decrease of between 0.2 and $0.3 \mathrm{M} \mathrm{NaCl}$ was found for the system used in this study (Figure 6b).

As conformational changes can be clearly attributed to the neutralizing effect cations have on the negative charge of DNA, a clear distinction between the various DNA phase-separation processes, such as compaction, condensation, aggregation, and precipitation, is difficult. During DNA compaction, the molecular volume of single DNA molecules dramatically decreases, and compact DNA represents an extremely tightly packed polymer chain that approaches the physical limits of molecular compaction. While the compaction of giant T4 DNA was found to proceed as an all-or-none-type transition, ${ }^{18,21}$ the overall behavior of a DNA solution undergoing conformational changes appears to be a continuous process when solely examining the physicochemical properties of the DNA ensemble. ${ }^{16}$ Furthermore, given that the all-or-none nature of the transition is strong, the folded compact DNA molecules behave like a soluble colloid and tend to stay in solution without forming an assembly/aggregate. With an increase in condensing agent, the colloidal nature of compacted DNA becomes weaker, and DNA particles stick to each other, forming large aggregates or precipitates caused by collision between polymer particles. ${ }^{16,25}$ Sedimentation studies in the presence of poly(ethylene oxide) (PEO) and salt showed further that, in dilute DNA solutions, each molecule collapses into a more or less compact state. ${ }^{26}$ At appreciable DNA concentration, the collapse would be followed by collisions and coalescence of the particles. ${ }^{27}$

Applying different solution conditions and dilute T4 DNA concentrations, a consistent reduction in size from $\sim 3.3-3.5$ to $\sim 0.5-0.7 \mu \mathrm{m}$ was found when comparing DNA size prior to and after the coil-globule transition. ${ }^{9,17,20}$ In contrast to this reduction in single molecule size, an increase in the solute size was found in the present study (Figure 7a,b). The increase, however, can be attributed to the coalescence and aggregation of the single molecule particles due to the high concentration used. ${ }^{27}$ This is further confirmed as the aggregate size proved to be a function of [pDNA] (Figure 7b).

For further studies, $\mathrm{Na}^{+}$was replaced by $\mathrm{K}^{+}$as the cation of the phase-forming salt. The general difference in the results obtained with $\mathrm{K}^{+}$corresponds to the findings of Zinchenko and Yoshikawa ${ }^{20}$ showing that, with the exception of $\mathrm{Li}^{+}$, different monovalent cations influence the psi condensation according to their ionic radius. When using $\mathrm{PEG}_{\mathrm{MW} 3000}$ and $\mathrm{PEG}_{\mathrm{MW} 10000}$ at $[\mathrm{PEG}]=100 \mathrm{mg} / \mathrm{mL}$, the necessary salt concentrations for $\left[\mathrm{Na}^{+}\right] /$ $\left[\mathrm{K}^{+}\right]$causing $50 \%$ condensation were determined to be $0.33 /$ $0.53 \mathrm{M}$ and $0.14 / 0.21 \mathrm{M}$, respectively. ${ }^{20}$

Solubility of the pDNA Coil/Globule Transition. While single DNA molecules in the globule state remain in solution, larger aggregates are easily removed by centrifugation, ${ }^{28}$ allowing the monitoring of changes in the pDNA conformation/aggregation state by using simple solubility studies, as shown in Figure 5.

The cooperative effect of $\left[\mathrm{K}^{+}\right]$, $[\mathrm{PEG}]$, and $\mathrm{PEG}_{\mathrm{MW}}$ agrees well with the long-established psi condensation process of DNA. ${ }^{8,26}$ Since DNA compaction under such conditions can be

(25) Makita, N.; Yoshikawa, K. Proton concentration ( $\mathrm{pH}$ ) switches the higherorder structure of DNA in the presence of spermine. Biophys. Chem. 2002, 99 (1), 43-53.

(26) Lerman, L. S. Transition to a Compact Form of DNA in Polymer Solutions. Proc. Natl. Acad. Sci. U.S.A. 1971, 68 (8), 1886-1890.

(27) Jordan, C. F.; Venable, J. H.; Lerman, L. S. Structure and circular-dichroism of DNA in concentrated polymer-solutions. Nature (London), New Biol. 1972, 236 (64), 67-70.

(28) Kleideiter, G.; Nordmeier, E. Poly(ethylene glycol)-induced DNA condensation in aqueous/methanol containing low-molecular-weight electrolyte solutions Part II. Comparison between experiment and theory. Polymer 1999, 40 (14), 4025-4033. considered a model of DNA compaction in the protein-crowded environment inside living cells, a high number of studies examining these systems and their dependencies exist. ${ }^{16,18,20-22,27,28}$ The results shown in Figure $5 \mathrm{~b}$ indicate a coil-globule-coil transition depending on $[\mathrm{PEG}]$ and $\left[\mathrm{K}^{+}\right]$. When compared to the corresponding partitioning studies shown in Figure 2b,c only the secondary globule-coil transition is mirrored, while the first coil-globule transition lies outside the conditions, leading to a two-phase system. The resolvation effect shown in Figure 5b corresponds to findings by Vasilevskaya et al., ${ }^{21}$ who reported a reentrant decollapse of DNA in concentrated PEG solutions. As this effect yet awaits a theoretical explanation, it has been shown in Figure 2b,c that this "secondary" globule-coil transition leads to a reduced mass balance in the investigated ATPSs when compared to a "primary" coil-globule transition. This effect might be further enhanced by a reduction in bottom-phase solubility. It was shown earlier by Frerix et al. ${ }^{5}$ that the missing pDNA could be located as a precipitate in the interphase of the ATPS. When mixing the respective ATPSs prior to sampling, a closed mass balance could be obtained.

A similar effect was observed by Mikhailenko et al. ${ }^{29}$ when investigating the effect of temperature on the helix-coil and coil-globule transitions of T4 DNA. In the presence of 25 and $50 \%$ v/v tert-butyl alcohol, a coil-globule transition could be observed at temperatures above 50 and $40^{\circ} \mathrm{C}$, respectively. With a further increase to temperatures above 60 and $50{ }^{\circ} \mathrm{C}, \mathrm{AFM}$ analysis indicated a reentrant decollapse of the globule confirmation. UV measurement, however, revealed a helix-coil transition, i.e., melting of the double-stranded DNA into a soluble single-stranded DNA. It is, however, yet unclear whether this finding can be used to explain the secondary globule-coil transition observed in Figure 5b. This even more, since tertbutyl alcohol might potentially reduce the melting point of DNA while increasing salt concentration, generally leads to an increase in the melting point. Connected to their investigations, it also became clear that DAPI-labeled DNA proved to be more stable toward DNA denaturation, and thus melting temperatures are shifted to higher values. As this finding affects all AFM studies, care has to be taken when comparing results based on AFM to studies examining native DNA. Nevertheless, the decrease in solubility with increasing temperature seen in Figure 5d clearly reflects a coil-globule transition. The rather low critical temperature can be attributed to a cooperative effect of condensing agents $\left[\mathrm{K}^{+}\right] /[\mathrm{PEG}]$ and temperature corresponding to studies where a combination of divalent cations and elevated temperature led to a coil-globule transition. For DNA in its globule state, a further increase in temperature might again lead to a resolvation effect or globule-coil transition, as found by Mayama and Yoshikawa. ${ }^{30}$

Finally, the general role of $\mathrm{pH}$ changes on the coil-globule transition is yet unclear; however, a cooperative effect with other condensing agents has been reported. ${ }^{25}$

The qualitative agreement between the findings in the literature with the experimental results in this study thus leads us to the conclusion that the system parameters present in the respective phases of the ATPS initiate a coil-globule transition of the present pDNA, followed by the aggregation of single globule entities.

Partitioning of pDNA in ATPSs. Because of a difference in the partitioning of anions and cations in an ATPS, a Galvanitype interfacial electrostatic potential difference forms. In PEG/

(29) Mikhailenko, S. V.; Sergeyev, V. G.; Zinchenko, A. A.; Gallyamov, M. O.; Yaminsky, I. V.; Yoshikawa, K. Interplay between folding/unfolding and helix/coil transitions in giant DNA. Biomacromolecules 2000, I (4), 597-603.

(30) Mayama, H.; Yoshikawa, K. Thermodynamics in folding transition of DNA. Macromol. Symp. 2000, 160, 55-60. 
phosphate systems, this electrostatic potential difference is positive (see also Table 2) and thus favors the partitioning of net negatively charged biopolymers into the PEG-rich top phase. ${ }^{23}$ For PEG/ dextran systems, it has been further shown that the secondary structure of nucleic acids influences partitioning to a high degree. It was found that double-stranded nucleic acids showed the highest partitioning coefficient, while a clearly lower value for the partitioning coefficient was found for single-stranded or denatured nucleic acids. Interestingly, supercoiled forms of double-stranded DNA showed a 6-12-fold lower partitioning coefficient than the linear or nicked form in the employed PEG/dextran systems. ${ }^{7}$ As results obtained with the PEG/dextran system cannot be directly related to PEG/salt systems, these findings clearly indicate the strong and selective potential of ATPSs for different conformational forms of nucleic acids. Investigations into the secondary structure of DNA when treated with high concentrations of various condensing agents such as PEG, PEO, or multivalent cations showed a significant change in the $\mathrm{CD}$ spectrum prior to and after the coil-globule transition. ${ }^{8,9,27,31}$ In addition, the coil-globule transition introduces an additional drastic change in the shape and effective volume, reducing, for example, the effective volume of T4 DNA by a factor of $10^{4}-10^{5} .{ }^{16}$ It was further propagated that the inner part of the compact state could be compared with some sort of microionic crystal where cationic counterions are associated with the phosphate groups, while, at the same time, the compact particle behaves as a soluble colloid because of the surviving negative charge on the surface. ${ }^{16,25}$ This means that the overall effective negative charge directing nucleic acids into the top phase of PEG/phosphate systems will be reduced by several orders of magnitude. Finally, as seen in Figures 4 and

(31) Naimushin, A. N.; Quach, N.; Fujimoto, B. S.; Schurr, J. M. Effect of poly(ethylene glycol) on the supercoiling free energy of DNA. Biopolymers 2001, 58 (2), 204-217.

(32) Widom, J.; Baldwin, R. L. Cation-induced toroidal condensation of DNA studies with Co3+(NH3)6. J. Mol. Biol. 1980, 144 (4), 431-53.

(33) Kimura, K.; Kobayashi, H. Yeast RNA partition accompanying adsorption in salt PEG 2-phase system. Biotechnol. Tech. 1994, 8 (7), 473-478.

(34) Kimura, K.; Kobayashi, H. RNA partitioning accompanied by adsorption: High-molecular-mass RNA adsorbed at the interface like a particle. $J$. Chromatogr., B 1996, 680 (1-2), 213-219.
5, DNA in globule or even aggregated form will exhibit a higher sedimentation potential than will linearized forms of nucleic acids (see also refs 27-29). In view of the above-described changes in system properties, the observed qualitative agreement between the solubility behavior in Figure 5 and the partitioning behavior in Figure 2 strongly indicates a coil-globule transition of the pDNA. Additionally, electrostatic interactions will express a cooperative effect in the selective partitioning of pDNA and RNA and thus explain the shifts in critical values when comparing Figures 2 and 5. As shown previously, the coil-globule transition requires a certain length of the nucleic acid, so that DNA chains on the order of $100 \mathrm{bp}(\sim 30 \mathrm{~nm})$ cannot fold into a compact state, ${ }^{29,32}$ and thus small RNA and DNA fragments will not be able to follow pDNA into the bottom phase. Finally, findings by Kimura and Kobayashi ${ }^{33,34}$ and Frerix et al. ${ }^{5}$ showed that, when using a PEG/salt ATPS that is enforced by an increase in PEG molecular weight, high molecular mass RNA was preferentially adsorbed at the interface of the system.

\section{Conclusions}

Following the above reasoning, the discrete change in the partitioning behavior of pDNA in a PEG/salt system can be attributed to a coil-globule transition of the DNA molecule, altering its shape, size, and surface properties, combined with an electrostatic potential difference in the respective phase system. This highly sensitive structural change offers a unique opportunity when separation of pDNA from contaminating RNA or small gDNA fragments is required. A qualitative understanding of this highly complex interplay of two polymeric systems might thus lead to improved purification processes in the field of nucleicacid separations.

Acknowledgment. The authors thank QIAGEN GmbH for financial support of this study. We are also grateful to Claudia Schuster of the University of Applied Science, Jülich, Germany, for determinations of $\mathrm{K}+$ ions in the various ATPSs.

LA052745U 